\title{
Correction to: Villaret syndrome as clinical presentation of occult metastatic breast cancer
}

\author{
Luca Magistrelli $^{1,2}$ - Claudia Varrasi ${ }^{1}$ - Alessandro Stecco $^{3}$ - Alessandro Carriero ${ }^{3}$. \\ Roberto Cantello ${ }^{1}$
}

Published online: 6 November 2017

(C) Springer-Verlag Italia S.r.1. 2017

\section{Correction to: Neurol Sci (2017)}

https://doi.org/10.1007/s10072-017-3122-3

The author's given name and family name were initially interchanged inadvertently. The correct names have been corrected above. The original article was corrected.

The online version of the original article can be found at https://oi.org/ 10.1007/s10072-017-3122-3

Luca Magistrelli

magis.luca@gmail.com

1 Department of Translational Medicine, Section of Neurology,

University of Eastern Piedmont, Novara, Italy

2 Ospedale Maggiore della Carità, Corso Mazzini 18,

28100 Novara, Italy

3 Department of Translational Medicine, Section of Radiology,

University of Eastern Piedmont, Novara, Italy 